\title{
Dicer Inactivation Leads to Progressive Functional and Structural Degeneration of the Mouse Retina
}

\author{
Devid Damiani, ${ }^{1}$ John J. Alexander, ${ }^{2}$ Jason R. 0'Rourke, ${ }^{3}$ Mike McManus, ${ }^{4}$ Ashutosh P. Jadhav, ${ }^{5}$ Constance L. Cepko, ${ }^{5}$ \\ William W. Hauswirth, ${ }^{2}$ Brian D. Harfe, ${ }^{3}$ and Enrica Strettoi ${ }^{1}$ \\ ${ }^{1}$ Neuroscience Institute, Italian National Research Council, 56100 Pisa, Italy, Departments of ${ }^{2}$ Ophthalmology and ${ }^{3}$ Molecular Genetics and Microbiology, \\ University of Florida College of Medicine, Gainesville, Florida 32608, ${ }^{4}$ Department of Microbiology and Immunology, University of California, San \\ Francisco, California 94142, and ${ }^{5}$ Department of Genetics, Harvard Medical School, Boston, Massachusetts 02115
}

\begin{abstract}
MicroRNAs (miRNAs) are small, highly conserved molecules that have been shown to regulate the expression of genes by binding to specific target mRNAs. Dicer, an RNase III endonuclease, is essential for the production and function of mature miRNAs, and removal of Dicer has been shown to disrupt many developmental processes. In this study, Dicer was removed specifically from the retina using a floxed Dicer conditional allele and the retinal Chx10Cre transgene. Retinal Dicer knock-out mice displayed a reproducible inability to respond to light. In addition, morphological defects were observed with the formation of photoreceptor rosettes at postnatal day 16, which progressed to more general cellular disorganization and widespread degeneration of retinal cell types as the animals aged. This was accompanied by concomitant decrease in both scotopic and photopic electroretinogram (ERG) responses. Interestingly, removing a single allele of Dicer resulted in ERG deficits throughout life but not to morphological abnormalities. Northern blot analysis of Dicerdepleted retinas showed a decrease in several miRNAs. The observation that progressive retinal degeneration occurred after removal of Dicer raises the possibility that miRNAs are involved in retinal neurodegenerative disorders.
\end{abstract}

Key words: Dicer; miRNA; photoreceptors; bipolar cells; rosettes; horizontal cells; retinal degeneration; ERG

\section{Introduction}

MicroRNAs (miRNAs) encode small 21-nucleotide (nt) singlestranded RNAs that recently have been shown to regulate gene expression in a large number of diverse organisms and tissues (Cao et al., 2006). In vertebrates, miRNAs most often function as negative regulators of gene expression by base pairing with the 3 '-untranslated region of target mRNAs while part of RNAinduced silencing complexes. More than 400 miRNAs have been identified in both mice and humans, and each miRNA has the potential to regulate hundreds of target genes (Lagos-Quintana et al., 2002; Ambros and Chen, 2007). It has been proposed that more than one-third of all human genes may be regulated by miRNAs (Lewis et al., 2005). Approximately 70\% of experimentally detectable miRNAs are expressed in the brain, and among those upregulated in a tissue-specific expression pattern in the embryo, half are brain specific/enriched (Babak et al., 2004; Barad et al., 2004; Miska et al., 2004; Sempere et al., 2004; Thomson et al., 2004; Cao et al., 2006).

\footnotetext{
Received 0ct. 24, 2007; accepted March 17, 2008.

This work was supported by National Institutes of Health (NIH) Grant R01-EY12654 and by the Italian National Research Council (E.S.); by NIH Grants EY011123, EY008571, EY13729, EY007132, and NS36302 and by grants from the Macula Vision Research Foundation, Foundation Fighting Blindness, Juvenile Diabetes Research Foundation and Research to Prevent Blindness (W.W.H. and J.J.A.); by the Howard Hughes Medical Institute and NIH Grant EYO 9676 (C.L.C.); by NIH Grant R03-DA22201 (M.M.); and by University of Florida start-up funds (B.D.H.).

Correspondence should be addressed to either of the following: Dr. Enrica Strettoi, Istituto di Neuroscienze CNR Via G. Moruzzi 1,56100 Pisa, Italy, E-mail: enrica.strettoi@in.cnr.it; or Dr. Brian D. Harfe at the above address, E-mail: bharfe@mgm.ufl.edu.

D0I:10.1523/JNEUROSCI.0828-08.2008

Copyright $\odot 2008$ Society for Neuroscience $\quad 0270-6474 / 08 / 284878-10 \$ 15.00 / 0$
}

miRNAs are processed by Dicer, a double-stranded RNAspecific endonuclease, from a nonfunctional $\sim 70$-nt precursor RNA to a functional 21-nt molecule (Ambros, 2003). Dicer null mice have been reported to die at embryonic day 7.5 (E7.5) (Bernstein et al., 2003), rendering it impossible to study the role Dicer may play in later stages of development or in adult tissues. To bypass the early lethality associated with the removal of Dicer in all tissues, we recently created a floxed conditional Dicer allele (Harfe et al., 2005). Using this allele in conjunction with tissuespecific cre alleles, we and others have inactivated Dicer in a number of discrete tissues during both embryonic and postnatal life (Harfe et al., 2005; Harris et al., 2006; O'Rourke et al., 2007). Because Dicer is required for the processing of miRNAs, removal of Dicer results in a significant decrease in functional miRNAs.

Despite their abundance in the brain, detailed functional studies of miRNAs in the nervous system have not been provided until very recently (Cuellar et al., 2008; Davis et al., 2008). In this study, we used the Dicer conditional mouse in combination with a retinal Chx10Cre transgenic line (Rowan and Cepko, 2004) to assess the role miRNA-mediated regulation of gene expression plays in the developing and adult murine retina.

Our data demonstrate that inactivation of Dicer in the retina results in progressive and widespread structural and functional abnormalities, culminating in loss of photoreceptor-mediated responses to light and extensive retinal degeneration. This is the first study of miRNA inactivation within the mammalian eye and suggests that miRNAs play an essential role in neural tissue homeostasis. The degenerative phenotype reported here raises the 
possibility that miRNAs may be involved in some retinal diseases and, perhaps more generally, in neurodegenerative disorders as suggested by recent results obtained in mice with a conditional knock-out of Dicer in Purkinje cells (Schaefer et al., 2007).

\section{Materials and Methods}

Generation and genotyping of Dicer flox $/$ Dicer ${ }^{\text {flox }}$; Chx10Cre mice. Construction and genotyping of the Dicer and Chx10Cre alleles has been described previously (Rowan and Cepko, 2004; Harfe et al., 2005). To create mice in which Dicer was inactivated in the retina, males containing the Chx10Cre transgene were crossed to females homozygous for the Dicer conditional allele. This cross generated animals in which one Dicer allele was removed in the retina ("heterozygous animals"). Heterozygous mice were then used to create Dicer flox $/$ Dicer flox; Chx10Cre animals (referred to as "CKO"). CKO animals were viable and did not contain any obvious systemic phenotypic defects. Dicer flox $/$ Dicer flox or $w t / w t$; Chx10Cre mice were used as wild-type controls in all experiments. All animals used in our analysis were outcrossed at least three times onto a C57BL/6 genetic background.

Dicer $^{\text {flox }} /$ Dicer $^{\text {flox }}$; Chx 10Cre animals were crossed to R26R mice (Soriano, 1999) to visualize cells that had undergone a recombination event.

Electrophysiology. Mice were dark adapted overnight in a Faraday shielded room, and all subsequent procedures were performed under dim red light $(>650 \mathrm{~nm})$. The corneas of the mice were given drops of $1 \%$ atropine, $2.5 \%$ phenylephrine, and $0.5 \%$ proparacaine (Akorn, Buffalo Grove, IL) for mydriasis and topical corneal anesthesia. The mice were then anesthetized by intraperitoneal injection $(6 \mu \mathrm{l} / \mathrm{g})$ of a sterile mixture of $100 \mathrm{mg} / \mathrm{ml}$ ketamine, $20 \mathrm{mg} / \mathrm{ml}$ xylazine, and normal saline at a 1:1:5 ratio, respectively. When the mice were fully sedated, they were placed onto a heated electroretinogram (ERG) platform in ventral recumbency. Balanced salt solution (Alcon, Ft. Worth, TX) and Gonak (Akorn) were used to lubricate the cornea before electrode placement. Custom platinum loop electrodes were positioned on the cornea using a three-axis micro-positioning system (Narishige, Tokyo, Japan). Grass (West Warwick, RI) platinum subdermal needle electrodes were used for ground and reference. All ERGs were performed using a Multiliner Vision (Jaeger/Toennies, Hochberg, Germany) system equipped with a Ganzfeldstimulator (Jaeger/Toennies). The Multiliner Vision apparatus complies with and exceeds the relevant International Society for Clinical Electrophysiology of Vision standards. Unless otherwise indicated, all mice were tested for dark-adapted ERG responses followed by light-adapted ERG responses. White light from a xenon source was used as the stimulus. For the scotopic (dark-adapted) ERG series, mice were exposed to a series of 10 flashes at $0.1 \mathrm{~cd} \cdot \mathrm{s} / \mathrm{m}^{2}$. For the photopic (light-adapted) ERG series, mice were exposed to background light at $100 \mathrm{~cd} / \mathrm{m}^{2}$ for $1 \mathrm{~min}$, and ERG recordings were done in the presence of a constant $100 \mathrm{~cd} / \mathrm{m}^{2}$ background light. Mice were then exposed to a series of 50 flashes at 10 $\mathrm{cd} \cdot \mathrm{s} / \mathrm{m}^{2}$. Right and left eyes were tested simultaneously, and the data were recorded. Analysis of the ERG waveforms for $\mathrm{a}$ - and b-wave maxima was performed using the Multiliner Vision software. Additional analysis was performed using SigmaPlot software. When calculating significance, a Student's $t$ test was used.

Northern blot. Retinas from 1 month ( $n=3$ mutant; $n=6$ wild type), 3 month ( $n=3$ mutant; $n=2$ wild type) and 24 month ( $n=2$ mutant; $n=3$ heterozygous; $n=2$ wild type) animals were pooled. RNA was isolated from fresh homogenized pooled retinas with TRI Reagent (Sigma, St. Louis, MO). Approximately $12 \mu \mathrm{g}$ of total RNA for the 1 and 3 month time points and $\sim 8 \mu \mathrm{g}$ of total RNA from 24 month animals was resolved on $10 \%$ urea/polyacrylamide gels and electroblotted to Hybond $\mathrm{N}^{+}$membranes (GE Healthcare, Little Chalfont, UK) at $200 \mathrm{~mA}$ for $3 \mathrm{~h}$. Blots were cross-linked using a Stratalinker (Stratagene, La Jolla, CA) and prehybridized for at least $1 \mathrm{~h}$ at $37^{\circ} \mathrm{C}$ in ULTRAhyb-Oligo (Ambion, Austin, TX) hybridization buffer before overnight incubation at $37^{\circ} \mathrm{C}$ in hybridization buffer containing the $\left[{ }^{32} \mathrm{P}\right]$-end-labeled probe. Probes were generated by end-labeling $20 \mathrm{pmol}$ of DNA oligonucleotide (Invitrogen, Carlsbad, CA) complementary to a specific miRNA or U6 with T4 polynucleotide kinase (New England Biolabs, Ipswich, MA) and 250 $\mu \mathrm{Ci}$ of $\left[\gamma^{-}{ }^{32} \mathrm{P}\right]$ ATP (PerkinElmer, Waltham, MA) followed by purifica- tion with MicroSpin G-25 columns (GE Healthcare). Blots were washed ( $2 \times$ SSC and $0.1 \%$ SDS) at $37^{\circ} \mathrm{C}$ for $30 \mathrm{~min}$ followed by two $30 \mathrm{~min}$ washes at room temperature. Blots were exposed to Kodak (Rochester, NY) BioMax film, and quantification was determined by densitometry of autoradiographs using ImageQuant TL version 2003.02 software. For subsequent probing, blots were stripped by incubating twice in boiling $1 \%$ SDS for $15 \mathrm{~min}$ each and were exposed to film to confirm that probes were removed.

In situ hybridization. Whole mouse eyes were fixed overnight in $4 \%$ paraformaldehyde (PFA)/PBS, infiltrated with $30 \%$ sucrose, frozen, and sectioned as described below. A 260-nt riboprobe (Harris et al., 2006), specific to the floxed Dicer exon, was used to assess Dicer distribution. After a brief wash in PBS, retinal sections were treated twice for $10 \mathrm{~min}$ with radioimmunoprecipitation assay buffer, postfixed $15 \mathrm{~min}$ in $4 \%$ PFA/PBS, and acetylated with $0.25 \%$ acetic anhydride in $0.1 \mathrm{M}$ triethanolamine. Slides were then prehybridized for $2 \mathrm{~h}$ in a solution of $50 \%$ formamide, $5 \times$ SSC, $5 \times$ Denhart's, $500 \mu \mathrm{g} / \mathrm{ml}$ salmon sperm DNA, and $250 \mu \mathrm{g} / \mathrm{ml}$ yeast RNA. Slides were hybridized for $12 \mathrm{~h}$ at $48^{\circ} \mathrm{C}$, with $100-300$ ng of digoxigenin-labeled probe per slide in a plastic chamber humidified with $50 \%$ formamide in $5 \times$ SSC. Posthybridization washes were made with $50 \%$ formamide and $0.1 \%$ Tween 20 in $2 \times$ SSC for $2 \mathrm{~h}$. Sections were then reequilibrated in $0.1 \%$ Tween 20 in $0.1 \mathrm{M}$ maleic acid buffer (MABT), blocked for $1-2 \mathrm{~h}$ in $10 \%$ sheep serum in MABT, and incubated for $12 \mathrm{~h}$ at $4^{\circ} \mathrm{C}$ with anti-digoxigenin-AP (1:2000 in blocking buffer; Roche, Basel, Switzerland). After MABT washing, the $\mathrm{pH}$ of the specimens was adjusted with $100 \mathrm{~mm}$ Tris, $\mathrm{pH} 9.5,50 \mathrm{mM} \mathrm{MgCl}_{2}$, and 100 $\mathrm{mm} \mathrm{NaCl}$. Finally, retinal sections were reacted for $1-2 \mathrm{~h}$ with nitroblue tetrazolium-5-bromo-4-chloro-3-indolyl phosphate solution (Sigma), washed in PBS, dehydrated in ethanol, mounted in DPX, and acquired with a Zeiss (Jena, Germany) Axioplan microscope, equipped with an AxioCam HRC color camera and dedicated AxioVision software.

Bromodeoxyuridine administration. Three intraperitoneal injections of $50 \mathrm{mg} / \mathrm{kg}$ bromodeoxyuridine (BrdU) were performed at $3 \mathrm{~h}$ intervals in postnatal day 35 (P35) mice $(n=5)$. Mice were then killed $3 \mathrm{~h}$ after the final injection, their eyes were prepared as described above, and BrdU was detected by immunocytochemistry (ICCH) on frozen retinal sections following the procedure of Close et al. (2005).

ICCH and electron microscopy. The eyes of mice aged P2, P16, P30, $45 \mathrm{~d}$ and 3-5 and 7 months were harvested, quickly enucleated, and immersion fixed for $1 \mathrm{~h}$ in $4 \%$ PFA in $0.1 \mathrm{~m}$ phosphate buffer (PB). The eyes were then rinsed in buffer, infiltrated overnight in $30 \%$ sucrose in $0.1 \mathrm{M} \mathrm{PB}$, embedded in OCT/Tissue Tek (Sakura Finetek, Zoeterwoude, The Netherlands), and frozen on a cryostat stage at $-25 /-30^{\circ} \mathrm{C}$. Eyes were sectioned vertically in $12-16 \mu \mathrm{m}$ serial sections with a Leica (Wetzlar, Germany) cryostat. Sections were collected on Superfrost Plus slides and air dried for $5 \mathrm{~min}$ to $2 \mathrm{~h}$. Slides were rinsed for $10 \mathrm{~min}$ with $0.01 \mathrm{M}$ PBS and blocked for $2 \mathrm{~h}$ in a solution containing $5 \%$ bovine serum albumin (BSA) and $0.3 \%$ Triton X-100 in PBS. Primary antibodies were diluted in $1 \%$ BSA and $0.1 \%$ Triton X-100 in PBS. Slides were incubated in primary antibodies for $12-18 \mathrm{~h}$ at $4^{\circ} \mathrm{C}$. Primary antibodies were rinsed off by two 10 min incubations in PBS at room temperature. Sections were then incubated for $2-4 \mathrm{~h}$ in solutions containing appropriate secondary antibodies, diluted 1:400, and conjugated with Oregon Green 488, Alexa Fluor 568, Alexa Fluor 647 (Invitrogen), or Cy-3 (Sigma). Sections were then rinsed in PBS and, if appropriate, counterstained with the fluorescent nuclear dyes BOBO-1 or TOTO-3 (Invitrogen).

Primary antibodies and dilutions were as follows: mouse antirhodopsin (1:2500; Sigma); rabbit anti-recoverin (1:2000; Chemicon, Temecula, CA); mouse and rabbit anti-protein kinase C- $\alpha$ [PKC- $\alpha$; 1:1000, clone MC5 (Sigma); and sc-208 (Santa Cruz Biotechnology, Santa Cruz, CA)]; mouse and rabbit anti-calbindin D-28k (1:2000, clone CB955; Sigma and Swant, Bellinzona, Switzerland); mouse anti-G0 $\alpha$ (1: 1000, MAB 3073; Chemicon); mouse anti-neurofilament $200 \mathrm{kDa}$ (1: 100, clone N52; Sigma); rabbit anti-mGluR6 (1:2000; from Dr. S. Nakanishi, Osaka University, Osaka, Japan); mouse anti-postsynaptic density protein 95 (PSD95; 1:500; AbCam, Cambridge, UK); mouse antiglutamine synthase (1:2000, MAB302; Chemicon); rabbit anti-glial fibrillary acidic protein (GFAP; 1:1000; Sigma); goat anti-choline acetyl transferase (1:500; Chemicon); mouse anti-Cre recombinase (1:1000, 
MAB3120; Chemicon); rabbit anti-green fluorescent protein (GFP)-Alexa Fluor 488 conjugate (1:1000; Invitrogen); rabbit antiphosphohistone H3 (1:400; Millipore, Billerica, MA); rabbit anti-atypical PKC (C20, 1:500; Santa Cruz Biotechnology); rabbit anti-zonula occludens-1 (1:200; Zymed, San Francisco, CA); rabbit anti-laminin (1:400; Sigma); guinea pig anti-vesicular glutamate transporter (1:500; Chemicon); and rabbit anti-vesicular GABA transporter (1:500; Synaptic System, Goettingen, Germany). Rabbit anti-S-cone opsin (1:1000; Chemicon) and Alexa Fluor 488-PNA lectins (1:400; Invitrogen) were used to label cone photoreceptors.

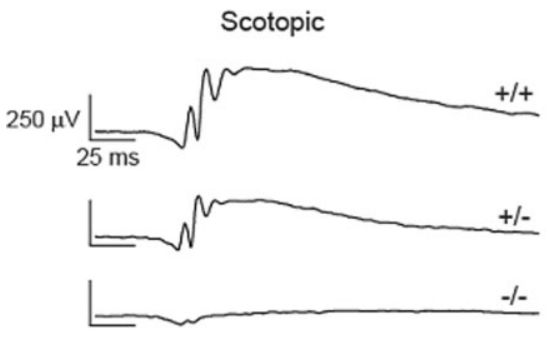

A

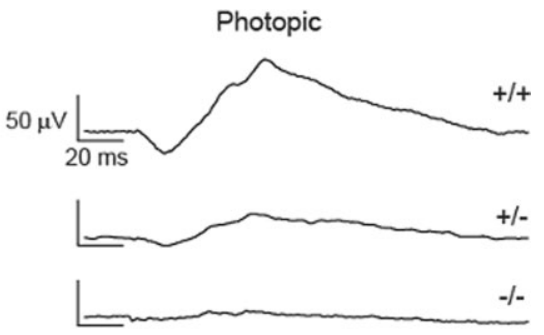

B

Figure 1. Representative scotopic $(\boldsymbol{A})$ and corresponding photopic $(\boldsymbol{B})$ ERG traces recorded at 5 months of age from wild-type, Dicer CKO heterozygous $(+/-)$, and Dicer CKO homozygous $(-/-)$ mice. Traces from each strain were similar at all time points analyzed.
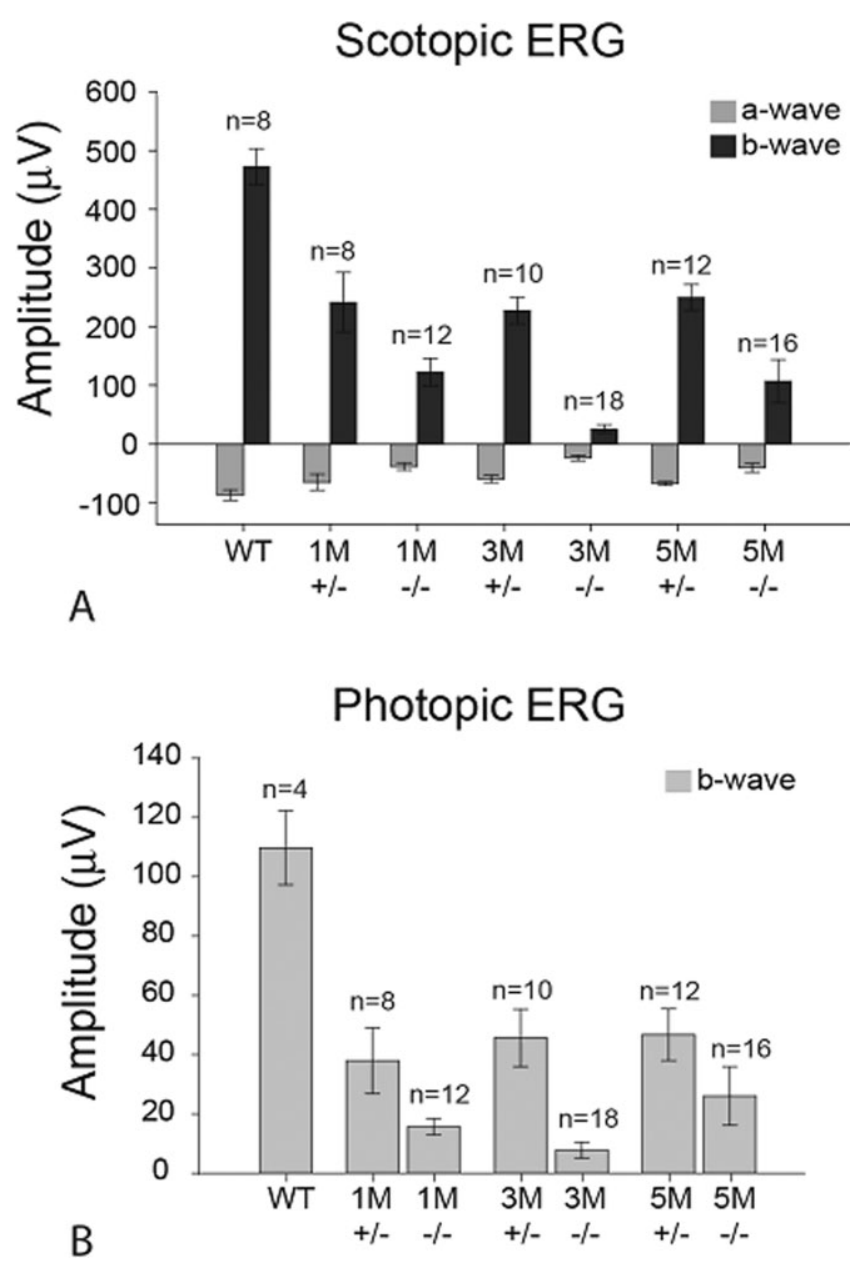

Figure 2. Average maximum scotopic a- and b-wave $(\boldsymbol{A})$ and photopic b-wave $(\boldsymbol{B})$ amplitudes for wild-type (WT), Dicer $+/-$, and Dicer $-/-$ eyes. $A$, Scotopic values for Dicer $+/-$ and Dicer $-/-$ at 1,3 , and 5 months differed from wild type and each other, with the exception of the 1 month a-wave value for the Dicer $+/-$. B, Photopic values for Dicer $+/-$ and Dicer $-/-$ eyes at 1,3 , and 5 months differed from wild type and each other, with the exception of the 5 month $b$-wave value between the Dicer $+/-$ and Dicer $-/-$. Different sets of mice were recorded at 1, 3, and 5 months, because the mice were killed the day after ERG for morphological studies. Error bars indicate SEM. M, Month.

Retinal preparations were examined with a Leica TCS-NT confocal microscope equipped with an argon-krypton laser or with a Leica TCS-SL spectral confocal microscope using high numerical-aperture oilimmersion objectives. Images acquired at a resolution of $1024 \times 1024$ were saved as TIFF files and exported on a workstation for off-line analysis. Retinas from at least one wild-type, one heterozygote, and three
CKO littermates for each age group $(2,16,30$, and $45 \mathrm{~d}$ and $3-5$ and 7 months) were used for ICCH and screened with the full panel of antibodies listed above. A total of 57 animals were analyzed for ICCH. Except for P2 and P16 animals, eyes used for morphological analysis were from animals previously used for ERG recordings (see below).

One additional litter composed of four mutants and five wild-type animals aged P2 was used for electron microscopy (EM) studies of immature retinas. After decapitation, the eyes were removed and immersion fixed in $2 \%$ PFA and $2.5 \%$ glutaraldehyde for $12 \mathrm{~h}$. After dissections, retinal tissue was postfixed in osmium tetroxide, bloc stained with $1 \%$ uranyl acetate, dehydrated in ethanol, and embedded in plastic. Semithin sections (1-2 $\mu \mathrm{m}$ thick) were stained with Epoxy Tissue stain (EMS, Hatfield, PA) and observed at the light microscope. Ultrathin sections from retinal blocs were counterstained with uranyl acetate and lead citrate and examined with a Jeol (Tokyo, Japan) 1200 EXII electron microscope. Photographs of retinal neuroblasts and differentiating photoreceptors were taken at $8000-20,000 \times$.

\section{Results \\ ERG abnormalities in CKO animals}

An analysis of ERGs recorded from 1-, 3-, and 5-month-old $\mathrm{CKO}$, heterozygous, and wild-type eyes revealed that the scotopic a- and b-wave (Fig. 1A) and photopic b-wave (Fig. $1 B$ ) amplitudes were diminished in both the CKO and heterozygous animals, with the CKO most severely affected. CKO eyes had the lowest amplitudes in all ERG tests and were significantly different from wild type (Fig. 2, Table 1). When compared with heterozygous eyes, all but two ERG measurements were significantly different (Fig. 2, Table 1). As a group, the heterozygous eyes were significantly different from wild type in all but one measurement (Fig. 2, Table 1). Both CKO and heterozygous eyes showed variability in the level of attenuation, consistent with the mosaic expression of the Chx10Cre allele (see below). The observed decrease in ERG function in heterozygous mice was unexpected, based on the lack of any detectable immunohistochemical defect in these animals. These data suggest that the proximal cause of such functional abnormalities may reside in molecular changes affecting phototransduction rather than retinal morphology.

Given the profound abnormality of ERG responses in all the $\mathrm{CKO}$ animals tested, and their progressive inability to respond to light, we performed a morphological analysis of their retinas attempting to establish a correlate between abnormal function and anatomical phenotype.

\section{Chx10Cre expression results in the mosaic inactivation of Dicer in the mouse retina}

As reported previously (Rowan and Cepko, 2004), Cre expression from the Chx10Cre transgenic allele does not drive cre expression in all retinal cells. As a result, not all cells in CKO retinas would be expected to lack a functional Dicer protein. To determine which 
Table 1. Significance values for the ERG amplitudes shown in Figure 2

\begin{tabular}{|c|c|c|}
\hline Scotopic a-wave & Scotopic b-wave & Photopic b-wave \\
\hline WT vs $1 \mathrm{M}-1-, p<0.001$ & WT vs $1 \mathrm{M}-/-, p<0.001$ & WT vs $1 \mathrm{M}-/-, p<0.001$ \\
\hline WT vs $1 \mathrm{M}+/-$, NS & WT vs $1 M+/-, p<0.005$ & WT vs $1 \mathrm{M}+1-, p<0.005$ \\
\hline $1 \mathrm{M}-/-$ vs $1 \mathrm{M}+/-, \mathrm{NS}$ & $1 \mathrm{M}-/-$ vs $1 \mathrm{M}+/-, p<0.05$ & $1 \mathrm{M}-/-$ vs $1 \mathrm{M}+/-, p<0.05$ \\
\hline WT vs $3 \mathrm{M}-1-, p<0.001$ & WT vs $3 \mathrm{M}-1-, p<0.001$ & WT vs $3 \mathrm{M}-1-, p<0.001$ \\
\hline WT vs $3 \mathrm{M}+1-, p<0.05$ & WT vs $3 \mathrm{M}+1-, p<0.001$ & WT vs $3 \mathrm{M}+1-, p<0.005$ \\
\hline $3 \mathrm{M}-1-$ vs $3 \mathrm{M}+1-, p<0.001$ & $3 \mathrm{M}-1-$ vs $3 \mathrm{M}+1-, p<0.001$ & $3 \mathrm{M}-1-$ vs $3 \mathrm{M}+1-, p<0.001$ \\
\hline WT vs $5 M-/-, p<0.005$ & WT vs $5 M-/-, p<0.001$ & WT vs $5 \mathrm{M}-/-, p<0.001$ \\
\hline WT vs $5 \mathrm{M}+1-, p<0.05$ & WT vs $5 \mathrm{M}+1-, p<0.001$ & WT vs $5 M+1-, p<0.005$ \\
\hline $5 \mathrm{M}-/-$ vs $5 \mathrm{M}+/-, p<0.01$ & $5 \mathrm{M}-/-$ vs $5 \mathrm{M}+1-, p<0.01$ & $5 \mathrm{M}-/-$ vs $5 \mathrm{M}+1-, \mathrm{NS}$ \\
\hline
\end{tabular}

WT, Wild type; M, month; NS, nonsignificant.

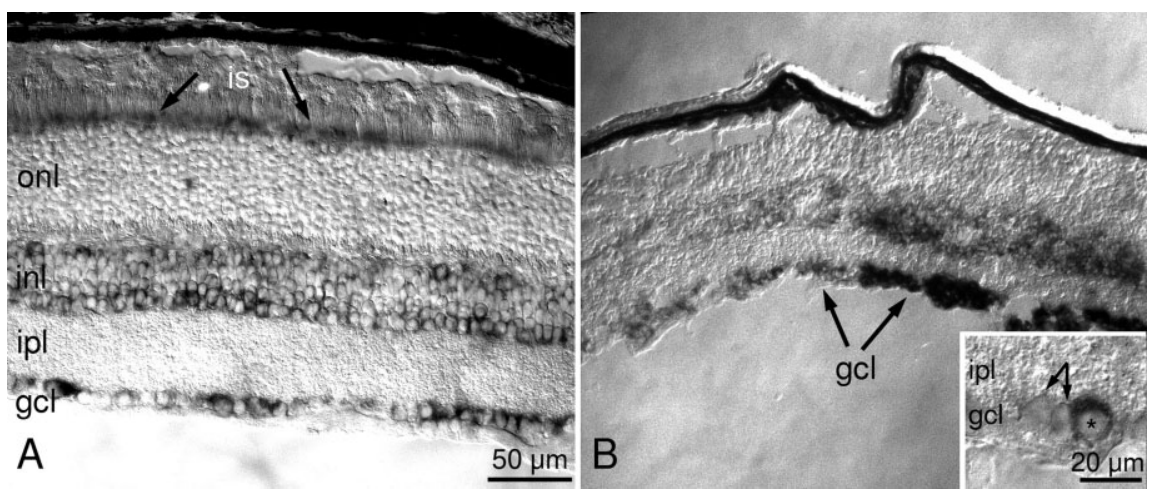

Figure 3. In situ hybridization for Dicer in wild-type (A) and CKO (B) retinas at P16. $\boldsymbol{A}$, In the wild-type animal, virtually all retinal cell types were labeled. Photoreceptor staining was concentrated within the inner segments (is; arrows) that contain the protein synthetic machinery, whereas the outer nuclear layer (onl), mostly containing their nuclei, was devoid of staining. The cytoplasm of cells of the inner nuclear layer (inl) and ganglion cell layer ( $\mathrm{gcl}$ ) also showed intense Dicer expression. $\boldsymbol{B}$, In the CKO, expression was more patchy than in the wild type. Most photoreceptors were negative, whereas cells in the gcl were either very intensely or relatively weakly stained (arrows). The inset shows a high magnification of the stained cells in the gcl. Arrows point to the somas of two negative cells adjacent to a larger cell, darkly stained (asterisk), all presumably ganglion cells. ipl, Inner plexiform layers.

retinal cells in CKO animals lacked Dicer, we performed RNA in situ hybridizations on retinal sections using a probe that was specific for the floxed exon in the Dicer conditional allele (Harris et al., 2006). In wild-type retinas, native Dicer was expressed in the vast majority of retinal cells (Fig. $3 A$ ). Staining in photoreceptors appeared localized in the inner segments. Some cells of the inner nuclear layer and ganglion cell layer were also labeled. Ganglion cells, possibly because of their abundant cytoplasm, appeared more intensely stained than other cell types.

In the P16 CKO retinas (Fig. 3B), Dicer expression was found to be patchy, with groups of labeled cells interdigitated with unlabeled cells. For example, cells in the ganglion cell layer were negative in some areas and positive in adjacent regions (Fig. 3B). To determine whether patchy expression of Dicer in CKO retinas was a reflection of the mosaic expression of the Chx10Cre driver, we examined Cre expression in CKO animals by means of antiCre antibodies. In the retinas of these mice, nuclei of cells in the inner nuclear layer, most likely bipolar cells, were stained as expected (Fig. 4). However, the pattern of labeling was not uniform but contained patches of Cre-negative cells contiguous to clusters of Cre-positive cells.

The cre gene is fused to GFP, and the fusion is run off the chx10 promoter (Rowan and Cepko, 2004). Therefore, we could also reveal cre-positive cells using anti-GFP antibodies. The pattern of staining obtained with either Cre or GFP antibodies was identical (data not shown). The mosaic expression of Dicer in the CKO retinas was also shown by staining for $\beta$-Gal on retinal sections obtained from mice containing the R26R cre-inducible reporter allele (Chx10Cre;R26R;Dicer ${ }^{\text {flox/ }}$ Dicer $\left.^{\text {flox }}\right)$. The R26R allele allowed for the detection of cells that had undergone a recombination event attributable to expression of cre recombinase from the Chx10Cre transgene (Soriano, 1999) (supplemental Fig. S1, available at www. jneurosci.org as supplemental material).

Our data indicate that Dicer inactivation using the Chx10Cre transgene results in the production of mosaic retinas in which Dicer null cells are located adjacent to Dicer-positive cells.

\section{Mosaic inactivation of Dicer in the retina leads to a decrease in retinal-specific miRNAs}

To determine whether partial Dicer inactivation in $\mathrm{CKO}$ retinas resulted in aberrant miRNA processing, we performed a small RNA Northern blot for miRNAs known to be expressed specifically in the retina or elsewhere in the CNS (miR-96, miR-124a, and miR-204). miR-96 and miR-204 are highly expressed in the developing and adult retina, whereas miR-124a is expressed throughout the entire CNS (Deo et al., 2006; Ryan et al., 2006; Karali et al., 2007). Northern blots were performed on pooled retinas from control and CKO animals (see Materials and Methods).

At 1 month, compared with wild type, the mature form of all three miRNAs examined was not changed (Fig. 5). At 3 months, mature miR-96 and miR-124 were found to be decreased $70 \%$ compared with wild type. At 2 years, mature miR-96 was decreased $63 \%$ and miR-124 was decreased $36 \%$. Interestingly, we observed a decrease in production of mature miR-96 and miR-124 in heterozygous retinas (Fig. 5). The decrease in miRNA levels in heterozygous retinas does not result in a phenotypic defect (see Fig. 10B) but may, at least partially, explain why heterozygous animals contained defective ERGs (Figs. 1, 2). A decrease in the number of retinal cells, compared with wild type, expressing the retinal-specific miRNA miR-183 was also detected in 7-month-old CKO retinas by means of RNA in situ hybridization (supplemental Fig. S2, available at www.jneurosci.org as supplemental material).

At all stages examined, miR-204 expression was unchanged (Fig. 5). miR-204 has been reported to be specifically expressed in a subset of cells in the inner nuclear layer of the retina (Deo et al., 2006). The Chx10cre allele used in our experiments is expressed in a very mosaic pattern in the inner nuclear layer (Fig. 4), which may be the cause of our inability to detect alterations in the expression of this particular miRNA in mutant animals. Both miR-124 and miR-96 have been reported to be broadly expressed throughout the retina (Karali et al., 2007; Xu et al., 2007). After removal of Dicer from the retina, cells undergo progressive cell death (see Figs. $9 D, 10 A)$. The increase in mature miRNAs found in Dicer null retinas at the 2 year time point compared with 3 months could be attributable to a decrease in the number of Dicer null cells present in the retina at this late stage. 

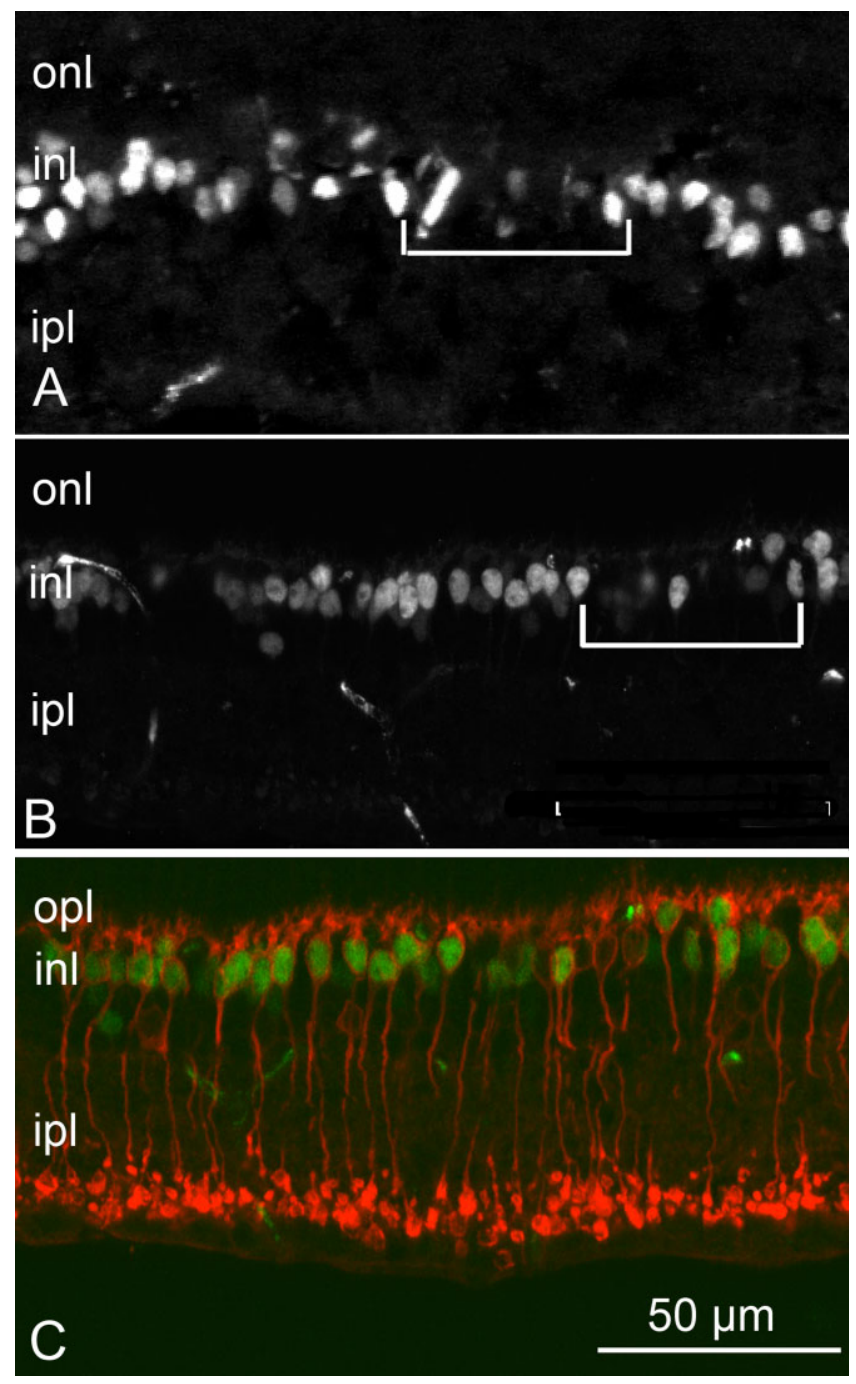

Figure 4. $\quad A$, Immunofluorescence staining with Cre antibodies in the CKO retina showing patchy expression of the transgene. $\boldsymbol{B}$, Patchy expression was also observed in the wild-type retina. Cre-negative cells (within the brackets) alternated with Cre-positive, fluorescent nuclei in the inner nuclear layer at the presumptive location of bipolar cells. C, Immunostaining for Cre (green) and PKC $\alpha$ (red) for rod bipolar cells. With few exceptions, rod bipolar cells were Cre positive. onl, Outer nuclear layer; opl, outer plexiform layer; inl, inner nuclear layer; ipl, inner plexiform layer.

\section{Retinal phenotype in CKO mice}

The most striking abnormal feature present in all CKO retinas aged P16 and older was the presence of photoreceptor rosettes (Fig. 6). Rosettes are circular structures, comprising photoreceptors only, that are oriented toward an internal lumen with photoreceptor outer segments protruding inward. Fragments of retinal pigment epithelial cells are also occasionally observed inside rosette lumen (data not shown).

In P16 mutants, rosettes were scattered along an otherwise normal retinal outer surface and were primarily composed of photoreceptors and their synaptic terminals (Fig. 6). The number and density of rosettes varied in each retina; however, each rosette was separated from the others and clearly identifiable even at low magnification. Interestingly, the presence of rosettes did not appear to alter the typical laminar organization of the retina: inner retinal layers were unperturbed by overlying rosettes, and the number of rows of photoreceptor nuclei in areas devoid of rosettes was found to be normal (12-14; data not shown). At this
A

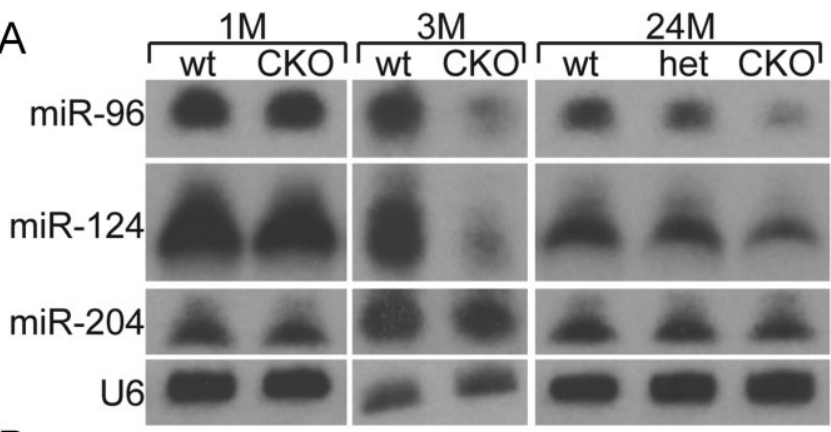

B

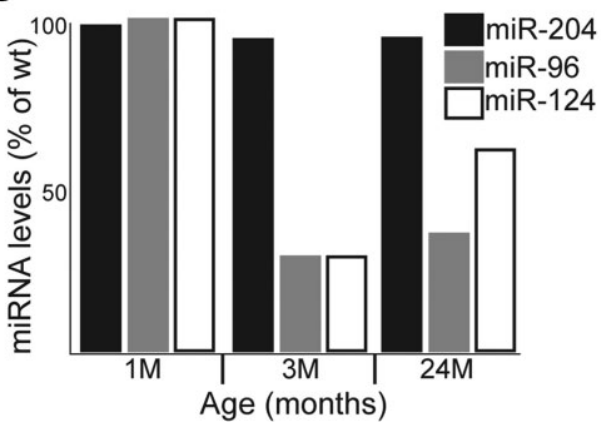

Figure 5. Northern blot analysis of mature miRNA levels from retinal homogenates of wildtype (wt), heterozygous (het), and mutant animals. $\boldsymbol{A}$, Northern blot analysis of equal amounts of RNA obtained from pooled samples of wild-type, mutant, and, at the 24 month time point, heterozygous retinas (see Materials and Methods). The small RNA U6 was used as a loading control. $\boldsymbol{B}$, Histogram of the relative expression levels for each miRNA examined on the Northern blot shown in $\boldsymbol{A}$. At the 24 month time point, miR-96 and miR-124a were decreased 18 and $10 \%$, respectively, in heterozygous retinas. No decrease in miR-204 expression was observed at any time point examined (see Results). Expression levels were normalized to wild type as described in Materials and Methods. M, Month.

early stage, the presence of rosettes was not accompanied by concomitant overexpression of GFAP in Müller cells. GFAP overexpression is a well known indicator of glial activation and is associated with retinal degeneration or perturbation in laminar organization (Marc et al., 2003). In the CKO animals, GFAP overexpression in Müller cells was only detected at later stages during which a clear loss of retinal cells was taking place (Fig. 9E).

Rosettes have previously been described in a number of pathological retinal conditions, including retinoblastoma (Yuge et al., 1995), diabetic retinopathy (Lahav et al., 1975), and retinitis pigmentosa (Tulvatana et al., 1999). In these diseases, retinal degeneration and/or abnormal proliferation are present (Lin et al., 2001). To test whether the formation of photoreceptor rosettes in Dicer depleted retinas was associated with an increase in cell proliferation in the photoreceptor layer, we treated P35 animals with BrdU. In addition, we stained sections from multiple P16 retinal samples with antibodies against phosphohistone H3, a specific marker of cell proliferation (Dhomen et al., 2006) (Fig. 7). Using either method, we failed to detect dividing cells in CKO retinas, although we observed, as expected, mitotic cells in other ocular tissues such as the cornea (Fig. 7). Thus, rosette formation did not appear to be caused by an upregulation in retinal cell proliferation.

To determine whether areas of rosette formation were those that had experienced Cre expression, tissue samples were labeled with anti-Cre antibodies. Rosettes were found in areas where bipolar cells expressed cre, suggesting that these structures formed as a result of a decrease in miRNA levels (Fig. 7). 

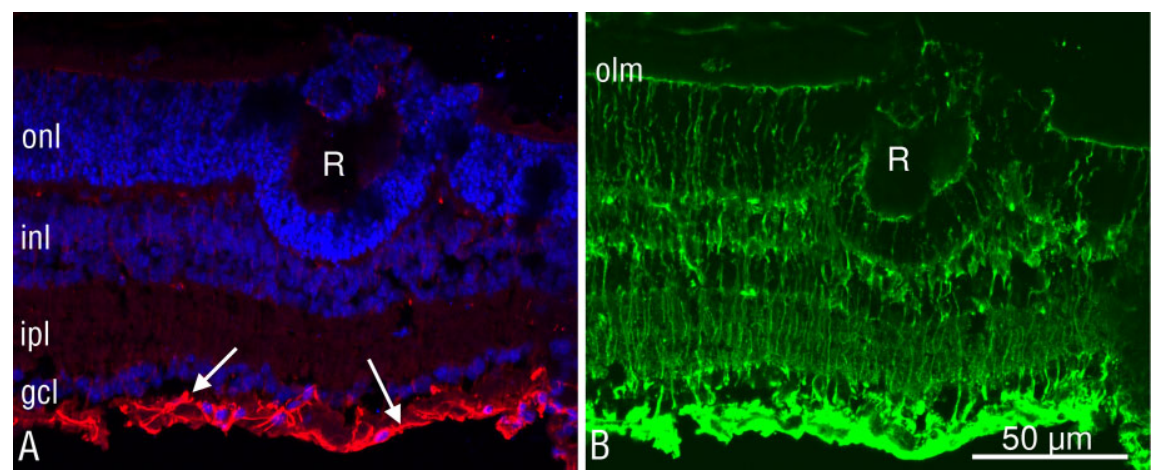

Figure 6. Representative rosette in a P16 Dicer CKO retinal section. $\boldsymbol{A}$, Nuclear staining (blue) demonstrated that the rosette (R) at this stage of development was composed exclusively of photoreceptors (identified by their distinctive nuclear morphology). GFAP staining (red) was limited to astrocytic processes in the ganglion cell layer (arrows), indicating that macroglial reactivity was virtually absent after removal of Dicer. $\boldsymbol{B}$, Rosettes did not appear to contain Müller cells because the Müller cell-specific enzyme glutamine synthase (green signal) did not colocalize with cells in the rosette. olm, Outer limiting membrane; onl, outer nuclear layer; inl, inner nuclear layer; ipl, inner plexiform layer; gcl, ganglion cell layer.

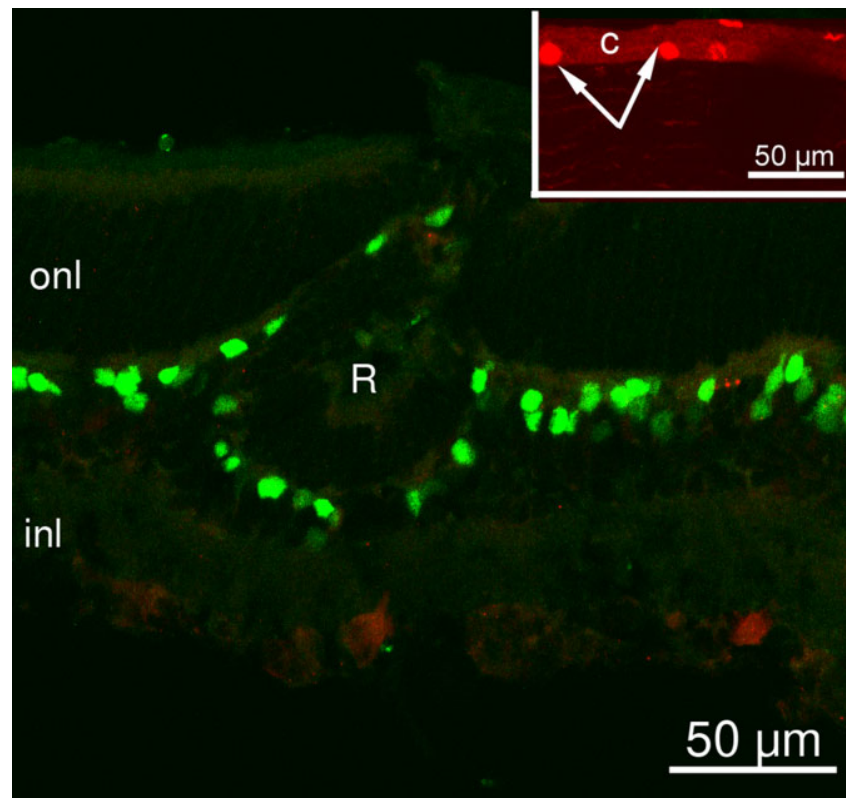

Figure 7. Vertical section of a P16 CKO retina, exhibiting a typical rosette (R), stained with antibodies against Cre (green) and phosphohistone H3 (red) to locate mitotic cells. No dividing (red) cells were visible. As a positive control, the inset shows mitotic cells of the corneal surface (C) from the same ocular section from which the retinal slide was obtained. onl, Outer nuclear layer; inl, inner nuclear layer.

\section{Developmental observations in Dicer CKO retinas}

Appropriate formation of retinal layers depends critically on the maintenance of apico-basal polarity in the neuroepithelial cells during early development. Retinal neuroblasts are joined by junctional complexes precisely positioned at the apico-basolateral domain of the cell membrane. Alterations of the molecular components controlling these complexes lead to abnormal retinal layering and subsequent rosette formation (Erdmann et al., 2003; Malicki et al., 2003; Masai et al., 2003; for review, see Malicki, 2004; Galli-Resta et al., 2008). To test the hypothesis that the rosettes observed in Dicer CKO mature retinas could be caused by major defects in the apico-basal polarity of neuroepithelial cells, we examined by ICCH and EM CKO and wild-type retinas at $2 \mathrm{~d}$ of age $(n=8$ animals for each genotype). We assessed (1) early retinal layering, (2) laminar position of dividing and differentiating cells, and (3) position of junctional complexes among differentiating photoreceptors and neuro- blasts. Results are illustrated in supplemental Figures S3 and S4, available at www. jneurosci.org as supplemental material.

This analysis demonstrated that immature Dicer CKO retinas did not contain major defects in neuroepithelial cell polarity or in the structure of adherens junctions, therefore indicating that rosettes, which are found in older mutant retinas, were not the result of improper patterning of these cell types.

\section{Characterization of cell types in CKO retinas}

The normal complement of retinal cell types, comprising neurons and glia (Jeon et al., 1998; Haverkamp and Wassle, 2000), were represented in the CKO retinas from P16 onward. Cells were observed to occupy the expected laminar positions, and the overall retinal architecture appeared normal. One exception, as discussed above, was the presence of rosettes at all stages examined. Using cell-type-specific antibodies, all major cell types including rods and cones (Fig. 8A), horizontal cells (Fig. 8B), rod and cone bipolar cells (Fig. $8 C, D$ ), various types of amacrine cells (Fig. $8 E$ ), and ganglion cells (Fig. $8 F$ ) were present in CKO retinas. All cells displayed normal morphology, pattern of stratification, and appropriate lamination in the plexiform layers. Retinal glial cells, in particular astrocytes and Müller cells (Fig. 7A,B), were also appropriately represented and positioned correctly in the $\mathrm{CKO}$ retinas.

The majority of rod bipolar cells were Cre positive, as demonstrated by anti-Cre (Fig. 8C) and anti-GFP antibodies (data not shown). As expected, Cre staining was nuclear and showed a similar pattern in the CKO and wild-type retinas (Fig. 4A,B). Cre-positive nuclei occupied the presumptive bipolar layer, and thus both rod and cone bipolar cells were Cre positive and presumably Dicer null. A few nuclei from Cre-positive, PKC $\alpha$-negative cells were larger in size and were presumably derived from Müller cells.

Using cell-type-specific antibodies, the data suggested that removal of Dicer in retinal progenitors and differentiated bipolar cells did not affect retinal cell fate or migration of cells to their wild-type locations during retinal development.

\section{From rosette formation to retinal degeneration in Dicer-depleted retinas}

The time period from P16 to P45 was characterized by progressive alteration and remodeling of the laminar retinal structure in CKO mice (Fig. 9). The number of rosettes increased (Fig. 9A), whereas their structure became more complex: bipolar and horizontal cells penetrated the rosettes, whereas photoreceptor clusters were displaced toward the outer retina (Fig. 9). The normal synaptic structures of the outer plexiform layer also became displaced toward the outer retina (Fig. $9 A, B$ ); concomitantly, the dendrites of both rod bipolar and horizontal cells sprouted profusely in the direction of the photoreceptors (Fig. 9C-E). Entire retinal domains appeared to be displaced outward, resulting in a progressive destruction of the external lamination of the P45 CKO retina. Most dramatically, PSD95, a marker of photoreceptor synaptic terminals, was expressed ectopically in the outer retina and reached the outer limiting membrane (Fig. 9A).

As $\mathrm{CKO}$ animals reached 3 months of age, the rosettes were observed to decrease in size and eventually disappear from the retina. Photoreceptors composing these rosettes degenerated, and the outer 
nuclear layer became progressively thinner. This was confirmed by detection of pyknotic nuclei in the outer and inner retina by using DNA-binding dyes (Fig. 10A). At 3 months, most rosettes had been lost and replaced by areas of extensive degeneration. Generally, the outer nuclear layer appeared to be more reproducibly thinner in the peripheral compared with the central retina, suggesting that the degenerative processes had a peripheryto-central gradient. At 3 months of age, in the extreme periphery, the outer nuclear layer was reduced at two to three rows (Fig. 9F).

Concomitant with outer retinal degeneration, the inner retina also deteriorated and exhibited cellular loss. Simultaneously, Müller cells became hypertrophic with their radial processes increasing in size and GFAP reactivity raising visibly, indicating a generalized glial activation (Fig. $9 F$ ). At the same time, Cre-positive cells became scarce, most likely because a large fraction of these Dicer null cells degenerated, as demonstrated by the progressive thinning of the inner nuclear layer. Surviving rod bipolars often occurred in clusters and had altered morphologies with axonal arborizations that were hypertrophic with enlarged, bulbous-like endings and dendrites that were scant and thicker than normal. PKC $\alpha$ staining was abnormally bright and had an unusually punctate appearance. Most of the residual rod bipolar cells were Cre negative (Fig. 9D) and therefore most likely originated from precursors in which Dicer was not inactivated because of the mosaic activity of the Chx10Cre transgenic allele (Rowan and Cepko, 2004).

\section{Heterozygous animals}

Retinas of animals in which a single copy of Dicer was inactivated in the retina (heterozygous animals) were examined by in situ hybridization, ICCH, and detailed confocal microscopy. Using these assays, no major defects were detected (Fig. 10). However, ERG recordings and Northern blot analysis (see above) did reveal functional abnormalities and a decrease in retinal miRNAs.

\section{Discussion}

The role miRNAs play in the development and maintenance of the nervous system is unknown. Dicerdeficient zebrafish exhibit abnormal morphogenesis and widespread abnormalities in neural development (Giraldez et al., 2005). However, many aspects of early embryonic development, including patterning and cell-fate specification are essentially unaffected by Dicer deletion in zebrafish, in part because of the inheritance of maternal Dicer. Dicer-deficient mice die during early development, around E7.5, and were found to be depleted of pluripotent embryonic stem cells (Bernstein et al., 2003). In the mouse nervous system, depletion of Dicer in Purkinje cells has
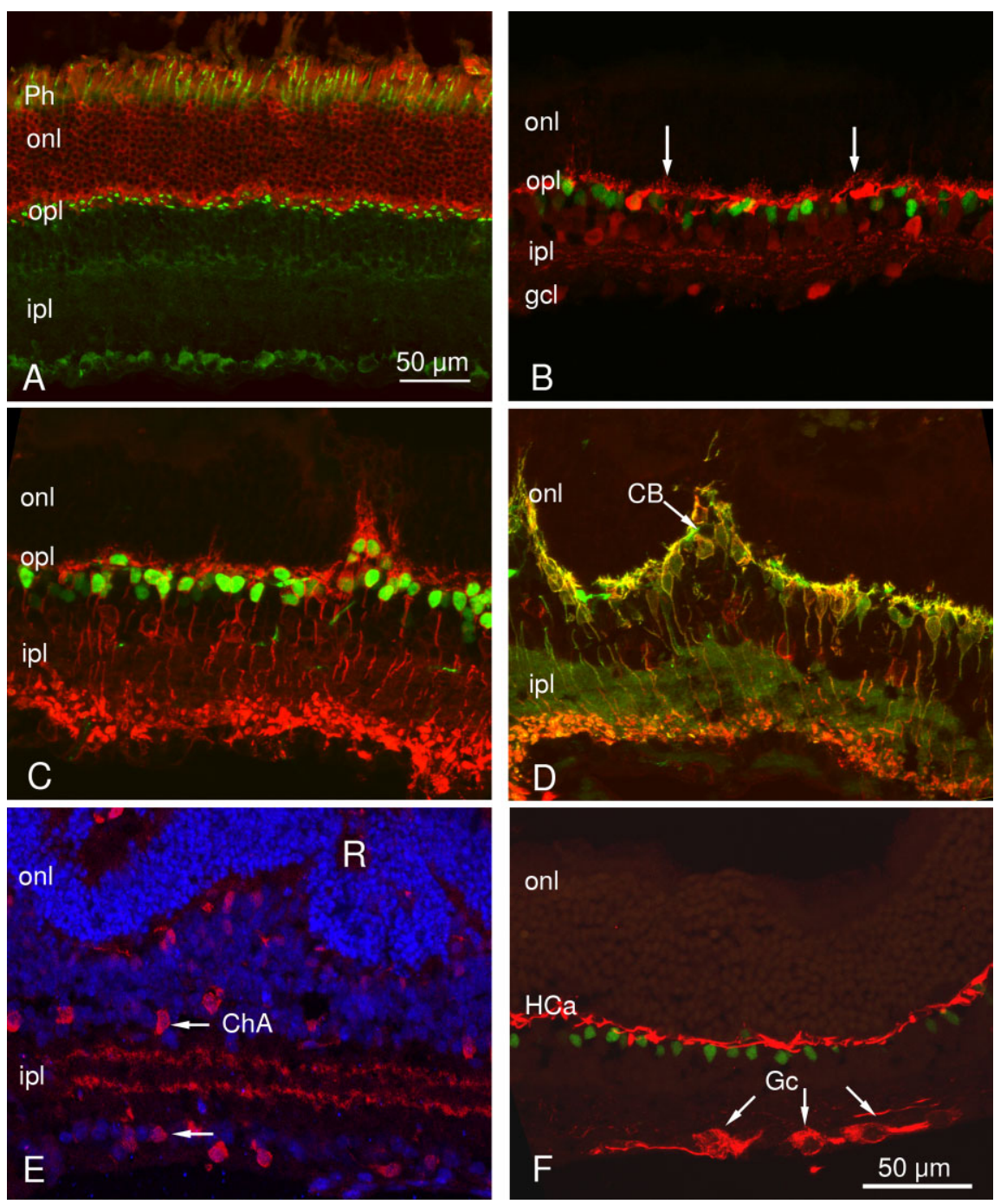

Figure 8. Characterization of cell types in the CKO retina. $A$, Rods and cones, labeled red by recoverin antibody, in a 3-monthold CKO retina; cones are counterstained green with peanut lectin. Their synaptic terminals formed a regular row in the outer plexiform layer, similar to what is observed in a normal retina. $B$, Horizontal cells, labeled red by calbindin D antibody, formed a tier in the outer part of the inner nuclear layer. Some of these sprouted ectopic neuritis toward the outer retina (arrows). The green signal denotes Cre staining. The section is from a P35 retina. C, Cre-positive nuclei (green) belong mostly to rod bipolar cells, the membranes of which are appropriately labeled red by an antibody against PKC $\alpha$. The section is from a P45 retina. D, Anti-G0 $\alpha$ antibodies (green) label ON-center cone and rod bipolar cells. PKC $\alpha$ antibody labels only rod bipolar cells (red). In this section, orange-yellow cells have been labeled by both antibodies and are therefore rod bipolar cells. Green cells are ON-center cone bipolar cells (CB). Some of these cells (arrow) appeared displaced toward the outer retina at a location adjacent to a photoreceptor rosette. The section is from a P45 retina. $\boldsymbol{E}$, Cholinergic amacrine cells (ChA; red) are seen in the CKO retina at the expected location. Their cell bodies formed two mirror-symmetric populations (arrows) in the inner nuclear and ganglion cell layers, respectively, whereas their processes formed two bands in the inner plexiform layer, characteristic to what is observed in the normal retina. Blue staining is a nuclear dye. The section is from a P30 retina. R, Rosette. F, Antibodies against the $200 \mathrm{kDa}$ subunit of neurofilaments (red) revealed the axonal arborizations of horizontal cells ( $\mathrm{HCa}$ ) and the somata of large ganglion cells (Gc) in the appropriate retinal layers. Green cells are stained with Cre antibodies. The section is from a P35 retina. Ph, Photoreceptors; onl, outer nuclear layer; opl, outer plexiform layer; ipl, inner plexiform layer; gcl, ganglion cell layer.

been reported to result in neuronal degeneration (Schaefer et al., 2007).

The results reported here highlight the crucial role Dicer and miRNAs play in the long-term regulation of retinal cell lamination, survival, and function. We have shown that removal of Dicer in the mouse retina had no visible impact on early postnatal retinal structure and function because retinal lamination appeared normal and all expected retinal cell types were represented. In addition, the relative widths of the various retinal layers appeared to be very similar between $\mathrm{CKO}$ and wild-type 


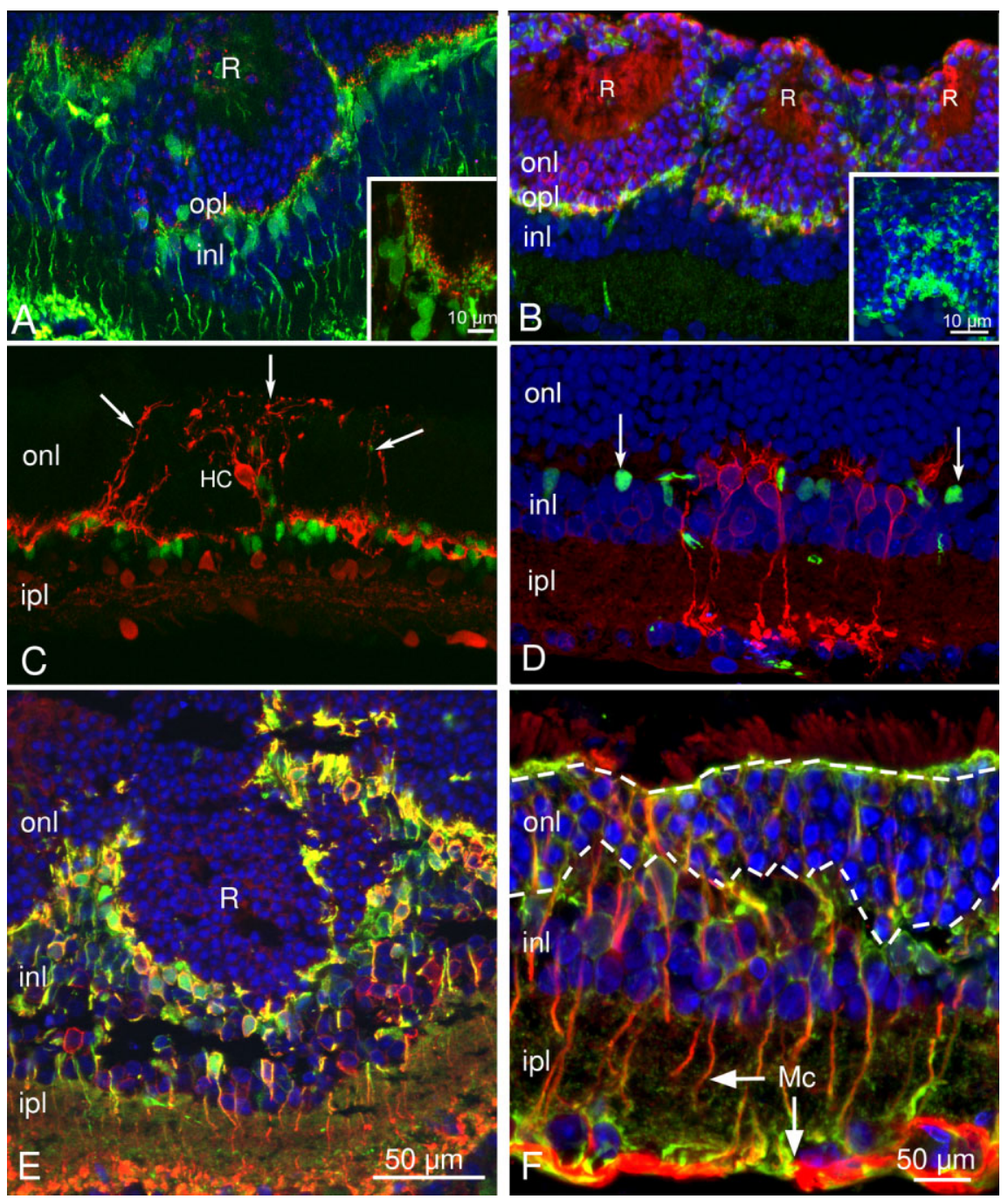

Figure 9. Progressive retinal remodeling and degeneration in P16 - P120 CK0 retinas. $\boldsymbol{A}$, Retinal section from a P16 animal. A large rosette (R) was penetrated by rod bipolar cells, labeled green by PKC $\alpha$ antibodies. These cells contained the normal complement of synaptic proteins, including the glutamate receptor mGluR6 (red). The inset shows at high magnification mGluR6-positive puncta decorating the dendritic tips of rod bipolar cells within a rosette. $\boldsymbol{B}$, Retinal section from a P30 animal. Three adjacent rosettes ( $R$ ) are revealed by antibodies against recoverin (red). Blue is nuclear counterstaining. PSD95, a marker of photoreceptor synaptic terminals (green), was mislocalized between the rosettes, indicating displacement of photoreceptor terminals to ectopic locations. Inset, Detail of ectopic expression of PSD95 (green) throughout the width of the outer nuclear layer. C, Concomitant with rosette formation, photoreceptors and second-order neurons were displaced to the outer retina and visibly remodeled in P35 retinas. The highlighted horizontal cell ( $\mathrm{HC}$ ), labeled red by calbindin D, sprouted profusely toward the outer retina (arrows), whereas the cell body migrated from the inner to the outer nuclear layer. The green stain is anti-Cre and thus denotes cells that are null for the Dicer protein. $\boldsymbol{D}$, At late stages, photoreceptors and inner retinal layers degenerated. Only three to five rows of photoreceptor nuclei remained in the outer nuclear layer of this 5-month-old retina. Rod bipolar cells, stained with PKC $\alpha(\mathrm{red})$, were scant and showed poorly preserved dendritic arborizations. These cells were Cre negative. A few Cre-positive cells (labeled green by anti-Cre antibodies) persisted in the inner nuclear layer (arrows). $\boldsymbol{E}$, In this large rosette (R) from a P45 retina, retinal layering was profoundly altered. Both rod and cone bipolar cells (stained red by PKC $\alpha$ and green by Go $\alpha$ antibodies) were present in the rosette and were found at ectopic retinal locations. Double-labeled cells (yellow) are rod bipolars, labeled by both antibodies. Scale bar in $\boldsymbol{E}$ applies also to $\boldsymbol{A}-\boldsymbol{D}$. $\boldsymbol{F}$, Glial activation accompanied retinal degeneration in 3-monthold CKO retinas. In this image, Müller glial cells (Mc) were stained both by glutamine synthase (green) and GFAP antibodies (red). The latter demonstrates that glial activation was widespread. Note the decrement in the number of photoreceptor rows to 2-5 from the 12-14 of a normal retina. onl, Outer nuclear layer; opl, outer plexiform layer; inl, inner nuclear layer.
It is important to note that the Cre allele used in these experiments, Chxiocre, drives Cre expression in the retina during embryogenesis. In both lung (Harris et al., 2006) and limb (Harfe et al., 2005), loss of Dicer resulted in a substantial decrease of all miRNAs examined $\sim 2 \mathrm{~d}$ after Cre expression. In our experiments in the retina, Dicer was removed $>20 \mathrm{~d}$ before ERG analysis and morphological detection of rosettes at P16. The presence of mature miRNAs at wild-type levels 1 month after birth indicates that either miRNAs in the retina are extremely stable or that an additional protein can compensate for DICER function in this tissue during early postnatal life. This is in stark contrast to what was observed in the mouse limb where Dicer removal almost immediately resulted in massive cell death (Harfe et al., 2005). The persistence of mature miRNAs in the Dicer CKO retina might explain the late degeneration of retinal cells observed in our experiments.

As CKO animals aged, we observed numerous defects in retinal structure including cell death. These observations suggest that miRNAs are initially required for the ability of the retina to respond to light, but not for cell survival. However, miRNAs play an essential role in maintaining the majority of cell types found in the adult retina.

Surprisingly, the light response deficit was observed in heterozygous in addition to homozygous animals suggesting that the level of Dicer protein was essential for proper function of the mouse retina. The light response defect was observed in all ages of retinas lacking a single Dicer allele, although we could detect no morphological defects in the retina of these heterozygous animals at any stage of life. These data suggest that either the mouse retina is extremely sensitive to the amount of mature miRNAs present or that Dicer has additional, non-miRNA functions in the mouse retina (see below). To our knowledge, this is the first demonstration in which the dosage of Dicer protein within a cell influences function. This light response deficit seen in heterozygote animals suggests one or more elements of the phototransduction cascade itself may be affected, because alteration here would likely quickly affect the ERG response but not retinal structure in the short term.

It is possible that not all the phenotypes we observed after removal of Dicer in the retina were attributable to the loss of ma-

retinas, although the perturbation to outer retinal surface in the vicinity of photoreceptor rosettes and the mosaic expression of the Dicer allele with alternation of normal and abnormal retinal patches made it virtually impossible to perform histograms of cell distributions. However, by 1 month of age the response to light was significantly diminished, and an abnormal retinal lamination clearly detectable. ture miRNAs. Dicer could be processing other double-stranded RNAs besides miRNAs within the targeted retinal cells. In addition, this enzyme could play a role in the nucleus as suggested by loss of centromeric and pericentromeric silencing in Dicer null embryonic stem cells (Kanellopoulou et al., 2005; Murchison et al., 2005).

Given the fact that the first sign of morphological abnormality 

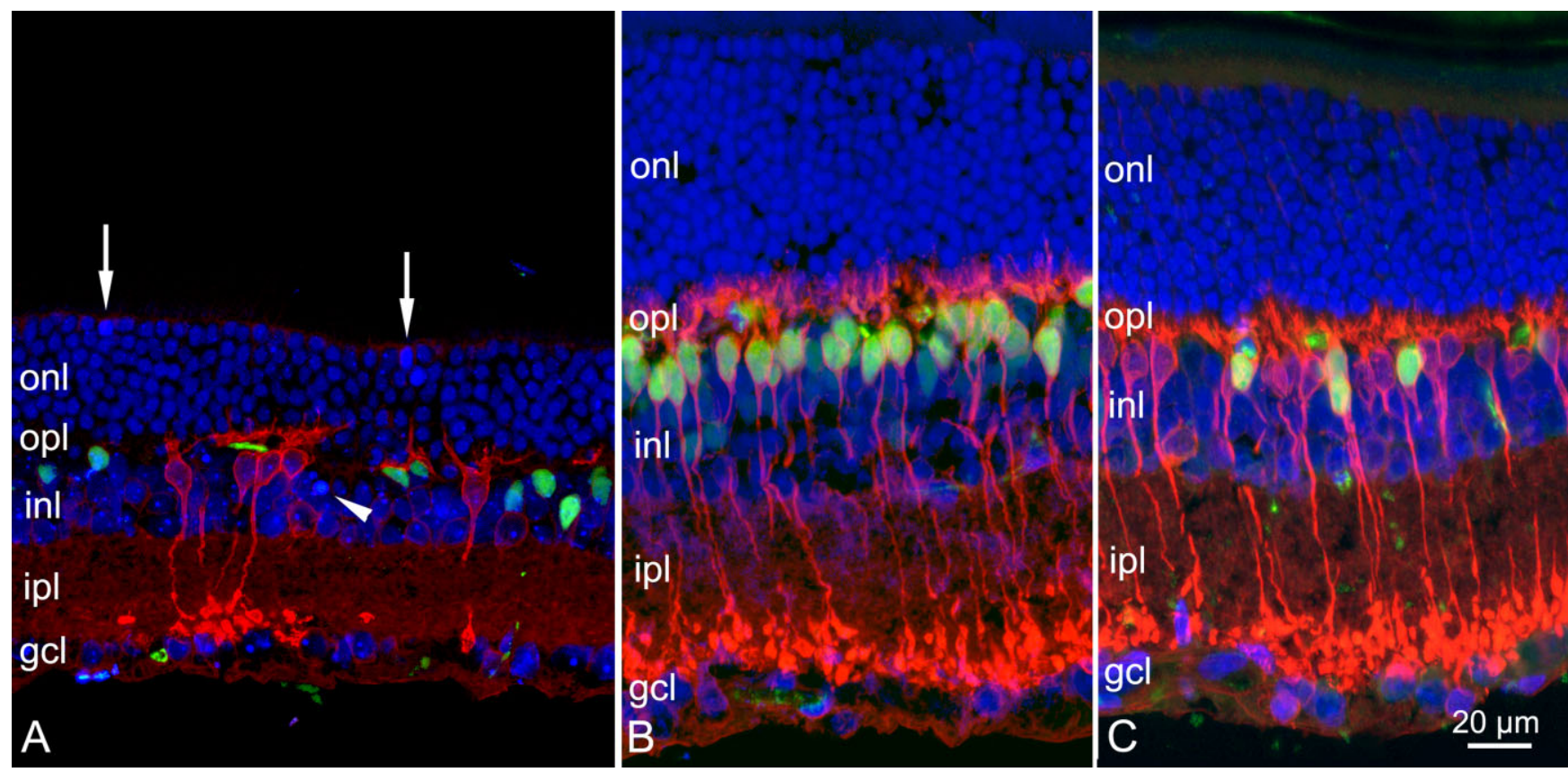

Figure 10. A, Extensive degeneration of the CKO retina at 5 months of age. Nuclei are stained blue by a fluorescent DNA-binding molecule. $B$, Compared with an age-matched, wild-type retina, all the layers of the CKO appeared thinner. Rod bipolar cells, labeled red by PKC $\alpha$ antibody, were significantly reduced in number and displayed only rare and disorganized dendrites compared with their counterpart in the wild-type retina. Surviving rod bipolar cells in the CKO were primarily Cre negative, whereas the number of Cre-positive cells (green labeling) was much decreased compared with the wild-type retina. Pyknotic nuclei, indicative of apoptotis, were visible in the outer nuclear layer (arrows) and in the inner nuclear layer (arrowhead) of the CK0 retina. $C$, Retinal section from a heterozygous animal, stained as the preparations shown in $\boldsymbol{A}$ and $\boldsymbol{B}$. No evident alterations of the morphology were detectable in heterozygous individuals. onl, Outer nuclear layer; opl, outer plexiform layer; inl, inner nuclear layer; ipl, inner plexiform layer; gcl, ganglion cell layer.

in $\mathrm{CKO}$ retinas was the formation of photoreceptor rosettes and that photoreceptor function was affected early, our data suggest that photoreceptors are the retinal cell type most sensitive to an imbalance in the production and maturation of miRNAs.

Photoreceptor rosettes are a common finding in a variety of retinal diseases. In particular, they are found in diabetic retinopathy, retinitis pigmentosa, and ischemia (Lahav et al., 1975; Yuge et al., 1995; Tulvatana et al., 1999). Rosettes have also been reported to result from decreased levels of secreted proteins of the Wnt family, shown to function as organizers of retinal lamination (Nakagawa et al., 2003). Rosette formation is usually associated with alteration of cytoskeleton, abnormal production of extracellular matrix and adhesion molecules (Li and Sakaguchi, 2004; Lunardi et al., 2006) in a variety of vertebrates, including Xenopus, zebrafish, chicken, mice, and humans.

Despite the fact that the exact trigger of rosette formation is not known, this common abnormality in retinal lamination might be caused early in development through alterations in polarity of neuroblasts (for review, see Malicki, 2004). To test this hypothesis, we compared wild-type and Dicer CKO retinas at $2 \mathrm{~d}$ of age, a time at which inner retinal layers are partially formed and the outer retina is still mostly composed of neuroblasts and differentiating photoreceptors (Sharma et al., 2003). Morphological examinations of retinal sections by ICCH and EM, aimed at assessing the proper orientation and polarity of neuroblasts, mitotic cells, developing photoreceptors and laminar position of differentiated cells, did not reveal major abnormalities. Adherens junctions in particular were found at their appropriate location at the outer retinal margin between differentiating photoreceptors and neuroblasts. These data were consistent with our observation that wild-type amounts of miRNAs were found during early postnatal development. Hence, it appears that rosette formation in the Dicer KO retina is not linked to major changes in neuroblast polarity or cell orientations and instead occurs after completion of retinal development.

Rosette formation may be followed by progressive photoreceptor death (Lin et al., 2001). This is similar to what we observed after removal of Dicer in the retina. Although the pattern of cell degeneration observed in mouse Purkinje cells after Dicer inactivation (Schaefer et al., 2007) bears similarity to neurodegenerative disorders such as Alzheimer's and Parkinson's disease, the pattern of retinal degeneration reported here does not precisely parallel genetically well understood forms of inherited retinal disease, such as retinitis pigmentosa. In both the human disease and in mouse models of this disorder, a clear rod-cone degeneration is observed first, whereas the degeneration of inner neurons, including horizontal and bipolar cells, is usually secondary (Gargini et al., 2007). This partially reflects the fact that the primary genetic defects typically occur in a photoreceptor-specific gene. In the Dicer CKO retina examined here, cellular death after P30 affected both rod and cone cell function simultaneously and was accompanied by a concomitant decrease in the number of second-order neurons. Interestingly, rod bipolar cells that persisted in retinas aged $\geq 3$ months were also Cre negative. Albeit their morphology was abnormal, the fact that these cells survived longer than Dicer null rod bipolars suggests the occurrence of cell-autonomous events in the genesis of the complex CKO phenotype.

At least 78 of the $>400$ miRNAs reported in mice are expressed in the retina (Xu et al., 2007). Because each miRNA could potentially regulate hundreds of genes, it is unclear what the role individual miRNAs may play in retinal development during embryonic and postnatal life. To unravel the exact role miRNAs play in rosette formation and/or ERG loss, the conditional removal of miRNAs specifically expressed in the retina, such as miR-183 (Karali et al., 2007), could be attempted.

Inactivation of Dicer in the mouse model used here likely 
resulted in a decrease in global levels of most retinal-expressed miRNAs. The unique pattern of retinal degeneration uncovered in this study is the first step toward identifying the overall role miRNAs contribute to retinal cell function and survival. Our results provide insight into the molecular mechanisms of retinal degeneration and the maintenance of normal retinal function and architecture.

\section{References}

Ambros V (2003) MicroRNA pathways in flies and worms: growth, death, fat, stress, and timing. Cell 113:673-676.

Ambros V, Chen X (2007) The regulation of genes and genomes by small RNAs. Development 134:1635-1641.

Babak T, Zhang W, Morris Q, Blencowe BJ, Hughes TR (2004) Probing microRNAs with microarrays: tissue specificity and functional inference. RNA 10:1813-1819.

Barad O, Meiri E, Avniel A, Aharonov R, Barzilai A, Bentwich I, Einav U, Gilad S, Hurban P, Karov Y, Lobenhofer EK, Sharon E, Shiboleth YM, Shtutman M, Bentwich Z, Einat P (2004) MicroRNA expression detected by oligonucleotide microarrays: system establishment and expression profiling in human tissues. Genome Res 14:2486-2494.

Bernstein E, Kim SY, Carmell MA, Murchison EP, Alcorn H, Li MZ, Mills AA, Elledge SJ, Anderson KV, Hannon GJ (2003) Dicer is essential for mouse development. Nat Genet 35:215-217.

Cao X, Yeo G, Muotri AR, Kuwabara T, Gage FH (2006) Noncoding RNAs in the mammalian central nervous system. Annu Rev Neurosci 29:77-103.

Close JL, Gumuscu B, Reh TA (2005) Retinal neurons regulate proliferation of postnatal progenitors and Müller glia in the rat retina via TGF beta signaling. Development 132:3015-3026.

Cuellar T, Davis T, Loeb G, Nelson PT, Harfe BD, Ullian E, McManus MT (2008) Dicer loss in striatal neurons produces behavioral and neuroanatomical phenotypes in absence of neurodegeneration. Proc Natl Acad Sci USA 105:5614-5619.

Davis TH, Cuellar TL, Koch S, Barker A, Harfe B, McManus MT, Ullian E (2008) Conditional loss of Dicer disrupts cellular and tissue morphogenesis in the cortex and hippocampus. J Neurosci 28:4322-4330.

Deo M, Yu JY, Chung KH, Tippens M, Turner DL (2006) Detection of mammalian microRNA expression by in situ hybridization with RNA oligonucleotides. Dev Dyn 235:2538-2548.

Dhomen NS, Balaggan KS, Pearson RA, Bainbridge JW, Levine EM, Ali RR, Sowden JC (2006) Absence of chx10 causes neural progenitors to persist in the adult retina. Invest Ophthalmol Vis Sci 47:386-396.

Erdmann B, Kirsch FP, Rathjen FG, More MI (2003) Ncadherin is essential for retinal lamination in the zebrafish. Dev Dyn 226:570-577.

Galli-Resta L, Leone P, Bottari D, Ensini M, Rigosi E, Novelli E (2008) The genesis of retinal architecture: an emerging role for mechanical interactions? Prog Ret Eye Res, in press.

Gargini C, Terzibasi E, Mazzoni F, Strettoi E (2007) Retinal organization in the retinal degeneration 10 (rd10) mutant mouse: a morphological and ERG study. J Comp Neurol 500:222-238.

Giraldez AJ, Cinalli RM, Glasner ME, Enright AJ, Thomson JM, Baskerville S, Hammond SM, Bartel DP, Schier AF (2005) MicroRNAs regulate brain morphogenesis in zebrafish. Science 308:833-838.

Harfe BD, McManus MT, Mansfield JH, Hornstein E, Tabin CJ (2005) The RNaseIII enzyme Dicer is required for morphogenesis but not patterning of the vertebrate limb. Proc Natl Acad Sci USA 102:10898-10903.

Harris KS, Zhang Z, McManus MT, Harfe BD, Sun X (2006) Dicer function is essential for lung epithelium morphogenesis. Proc Natl Acad Sci USA 103:2208-2213.

Haverkamp S, Wassle H (2000) Immunocytochemical analysis of the mouse retina. J Comp Neurol 424:1-23.

Jeon CJ, Strettoi E, Masland RH (1998) The major cell populations of the mouse retina. J Neurosci 18:8936-8946.

Kanellopoulou C, Muljo SA, Kung AL, Ganesan S, Drapkin R, Jenuwein T, Livingston DM, Rajewsky K (2005) Dicer-deficient mouse embryonic stem cells are defective in differentiation and centromeric silencing. Genes Dev 19:489-501.

Karali M, Peluso I, Marigo V, Banfi S (2007) Identification and characterization of microRNAs expressed in the mouse eye. Invest Ophthalmol Vis Sci 48:509-515

Lagos-Quintana M, Rauhut R, Yalcin A, Meyer J, Lendeckel W, Tuschl T
(2002) Identification of tissue-specific microRNAs from mouse. Curr Biol 12:735-739.

Lahav M, Albert DM, Craft JL (1975) Light and electron microscopic study of dysplastic rosette-like structures occurring in the disorganized mature retina. Albrecht Von Graefes Arch Klin Exp Ophthalmol 195:57-68.

Lewis BP, Burge CB, Bartel DP (2005) Conserved seed pairing, often flanked by adenosines, indicates that thousands of human genes are microRNA targets. Cell 120:15-20.

Li M, Sakaguchi DS (2004) Inhibition of integrin-mediated adhesion and signaling disrupts retinal development. Dev Biol 275:202-214.

Lin SC, Skapek SX, Papermaster DS, Hankin M, Lee EY (2001) The proliferative and apoptotic activities of E2F1 in the mouse retina. Oncogene 20:7073-7084

Lunardi A, Cremisi F, Dente L (2006) Dystroglycan is required for proper retinal layering. Dev Biol 290:411-420.

Malicki J (2004) Cell fate decisions and patterning in the vertebrate retina: the importance of timing, asymmetry, polarity and waves. Curr Opin Neurobiol 14:15-21.

Malicki J, Jo H, Pujic Z (2003) Zebrafish N-cadherin, encoded by the glass onion locus, plays an essential role in retinal patterning. Dev Biol 259:95-108.

Marc RE, Jones BW, Watt CB, Strettoi E (2003) Neural remodeling in retinal degeneration. Prog Retin Eye Res 22:607-655.

Masai I, Lele Z, Yamaguchi M, Komori A, Nakata A, Nishiwaki Y, Wada H, Tanaka H, Nojima Y, Hammerschmidt M, Wilson SW, Okamoto H (2003) N-cadherin mediates retinal lamination, maintenance of forebrain compartments and patterning of retinal neurites. Development 130:2479-2494.

Miska EA, Alvarez-Saavedra E, Townsend M, Yoshii A, Sestan N, Rakic P, Constantine-Paton M, Horvitz HR (2004) Microarray analysis of microRNA expression in the developing mammalian brain. Genome Biol 5:R68.

Murchison EP, Partridge JF, Tam OH, Cheloufi S, Hannon GJ (2005) Characterization of Dicer-deficient murine embryonic stem cells. Proc Natl Acad Sci USA 102:12135-12140.

Nakagawa S, Takada S, Takada R, Takeichi M (2003) Identification of the laminar-inducing factor: Wnt-signal from the anterior rim induces correct laminar formation of the neural retina in vitro. Dev Biol 260:414-425.

O’Rourke JR, Georges SA, Seay HR, Tapscott SJ, McManus MT, Goldhamer DJ, Swanson MS, Harfe BD (2007) Essential role for Dicer during skeletal muscle development. Dev Biol 311:359-368.

Rowan S, Cepko CL (2004) Genetic analysis of the homeodomain transcription factor Chx10 in the retina using a novel multifunctional BAC transgenic mouse reporter. Dev Biol 271:388-402.

Ryan DG, Oliveira-Fernandes M, Lavker RM (2006) MicroRNAs of the mammalian eye display distinct and overlapping tissue specificity. Mol Vis 12:1175-1184.

Sempere LF, Freemantle S, Pitha-Rowe I, Moss E, Dmitrovsky E, Ambros V (2004) Expression profiling of mammalian microRNAs uncovers a subset of brain-expressed microRNAs with possible roles in murine and human neuronal differentiation. Genome Biol 5:R13.

Schaefer A, O'Carroll D, Tan CL, Hillman D, Sugimori M, Llinas R, Greengard P (2007) Cerebellar neurodegeneration in the absence of microRNAs. Exp Med 204:1553-1558.

Sharma RK, O'Leary TE, Fields CM, Johnson DA (2003) Development of the outer retina in the mouse. Brain Res Dev Brain Res 145:93-105.

Soriano P (1999) Generalized lacZ expression with the ROSA26 Cre reporter strain. Nat Genet 21:70-71.

Thomson JM, Parker J, Perou CM, Hammond SM (2004) A custom microarray platform for analysis of microRNA gene expression. Nat Methods 1:47-53.

Tulvatana W, Adamian M, Berson EL, Dryja TP (1999) Photoreceptor rosettes in autosomal dominant retinitis pigmentosa with reduced penetrance. Arch Ophthalmol 117:399-402.

Xu S, Witmer PD, Lumayag S, Kovacs B, Valle D (2007) MicroRNA (miRNA) transcriptome of mouse retina and identification of a sensory organ-specific miRNA cluster. J Biol Chem 282:25053-25066.

Yuge K, Nakajima M, Uemura Y, Miki H, Uyama M, Tsubura A (1995) Immunohistochemical features of the human retina and retinoblastoma. Virchows Arch 426:571-575. 